\title{
MILBEMYCINS*, A NEW FAMILY OF MACROLIDE ANTIBIOTICS: FERMENTATION, ISOLATION AND PHYSICO-CHEMICAL PROPERTIES
}

\author{
Yo Takiguchi, Hiroshi Mishima**, Michihisa Okuda \\ and Michiya Terao
}

Fermentation Research Laboratories and **Central Research Laboratories Sankyo Co., Ltd., Shibakubo, Tanashi, Tokyo 188, Japan

Atsushi Aoki and RikiYa Fukuda

Research Laboratories, Hokkai Sankyo Co., Ltd., Toyohira, Sapporo 062, Japan

(Received for publication May 12, 1980)

\begin{abstract}
A search for novel insecticides has yielded the milbemycins, a new family of macrolide antibiotics with insecticidal and acaricidal activity. They are produced in submerged cultures of Streptomyces hygroscopicus subsp. aureolacrimosus. Fermentation studies on the strain were conducted in shaken flasks and 30-liter jar fermentors. From the culture broth 13 milbemycins were purified to homogeneity by column and thin-layer chromatography on silica gel and alumina. Physico-chemical data, such as mass spectra, UV and IR absorption spectra, optical rotations and melting points of the milbemycins are described.
\end{abstract}

In a search for novel insecticides, we discovered that the culture broth of a Streptomyces was active against acarus, harmful agricultural and horticultural insects such as aphids and larvae of insects of the order Lepidoptera. ${ }^{1)}$ The Streptomyces is a new subspecies and is designated S. hygroscopicus subsp. aureolacrimosus. Taxonomic studies will be reported elsewhere.

From the culture broth thirteen milbemycins were isolated and purified to homogeneity by column and thin-layer chromatography on silica gel and alumina. As reported briefly, ${ }^{2,3)}$ the milbemycins have the 16-membered macrolide structure shown in Fig. 1.

Subsequently the avermectins, isolated from the culture broth of Streptomyces avermitilis, were found to have structures closely related to the milbemycin $\alpha$ s, differing only in being substituted at the C-13 position by an oleandosyl oleandosyloxy moiety. ${ }^{4,5)}$

In this paper we describe the fermentative production, isolation and physico-chemical properties of the milbemycins.

\section{Materials and Methods}

Fermentation studies

Cultures were grown in Erlenmeyer flasks on a rotary shaker $(220 \mathrm{rpm}, 7 \mathrm{~cm})$ at $28^{\circ} \mathrm{C}$. Inocula were grown for 2 days in 500-ml Erlenmeyer flasks containing $50 \mathrm{ml}$ of seed medium with the following ingredients (in $\mathrm{g} / 1,000 \mathrm{ml}$ water): glucose 20 , soybean meal 10 , corn-steep liquor 5 and $\mathrm{NaCl} 3$. The $\mathrm{pH}$ of the medium was adjusted to 6.8 before autoclaving at $120^{\circ} \mathrm{C}$ for 20 minutes.

Production cultures in 100-ml Erlenmeyer flasks, each containing $30 \mathrm{ml}$ of the medium, were inoculated with $1 \mathrm{ml}$ of the seed culture. Fermentations with the Streptomyces were also conducted

* The antibiotics were initially designated as B-41. 
Fig. 1. Structures of milbemycins.

(1)

\begin{tabular}{|c|c|c|c|c|c|}
\hline $\begin{array}{l}\text { Milbemycins } \\
\text { (B-41) }\end{array}$ & $\mathrm{R}_{1}$ & $\mathrm{R}_{2}$ & $\mathrm{R}_{3}$ & $\mathrm{R}_{4}$ & $\mathrm{R}_{5}$ \\
\hline$\alpha_{1}\left(\mathrm{~A}_{3}\right)$ & $\mathrm{OH}$ & $\mathrm{CH}_{3}$ & $\mathrm{CH}_{3}$ & $\mathrm{H}$ & $\mathrm{H}$ \\
\hline$\alpha_{2}\left(\mathrm{~B}_{2}\right)$ & $\mathrm{OCH}_{3}$ & $\mathrm{CH}_{3}$ & $\mathrm{CH}_{3}$ & $\mathrm{H}$ & $\mathrm{H}$ \\
\hline$\alpha_{3}\left(\mathrm{~A}_{4}\right)$ & $\mathrm{OH}$ & $\mathrm{CH}_{3}$ & $\mathrm{C}_{2} \mathrm{H}_{5}$ & $\mathrm{H}$ & $\mathrm{H}$ \\
\hline$\alpha_{4}\left(\mathrm{~B}_{3}\right)$ & $\mathrm{OCH}_{3}$ & $\mathrm{CH}_{3}$ & $\mathrm{C}_{2} \mathrm{H}_{5}$ & $\mathrm{H}$ & $\mathrm{H}$ \\
\hline$\alpha_{5}\left(\mathrm{~A}_{2}\right)$ & $\mathrm{OH}$ & $\mathrm{CH}_{3}$ & $\mathrm{CH}_{3}$ & $\begin{array}{c}\mathrm{CH}_{3} \\
\mathrm{OCOCH}\left(\mathrm{CH}_{2}\right)_{3} \mathrm{CH}_{3} \\
\mathrm{CH}_{3}\end{array}$ & $\mathrm{OH}$ \\
\hline$\alpha_{\theta}\left(\mathrm{B}_{1}\right)$ & $\mathrm{OCH}_{3}$ & $\mathrm{CH}_{3}$ & $\mathrm{CH}_{3}$ & $\begin{array}{c}\mathrm{OCOCH}\left(\mathrm{CH}_{2}\right)_{3} \mathrm{CH}_{3} \\
\mathrm{CH}_{3}\end{array}$ & $\mathrm{OH}$ \\
\hline$\alpha_{7}$ & $\mathrm{OH}$ & $\mathrm{CH}_{3}$ & $\mathrm{C}_{2} \mathrm{H}_{5}$ & $\begin{array}{c}\mathrm{OCOCH}\left(\mathrm{CH}_{2}\right)_{3} \mathrm{CH}_{3} \\
\mathrm{CH}_{3}\end{array}$ & $\mathrm{OH}$ \\
\hline$\alpha_{8}$ & $\mathrm{OCH}_{3}$ & $\mathrm{CH}_{3}$ & $\mathrm{C}_{2} \mathrm{H}_{5}$ & $\mathrm{OCOC}+\mathrm{H}\left(\mathrm{CH}_{2}\right)_{3} \mathrm{CH}_{3}$ & $\mathrm{OH}$ \\
\hline$\alpha_{\theta}\left(\mathrm{C}_{1}\right)$ & $\mathrm{OH}$ & & $\mathrm{CH}_{3}$ & $\mathrm{H}$ & $\mathrm{H}$ \\
\hline$\alpha_{10}\left(C_{2}\right)$ & $\mathrm{OH}$ & & $\mathrm{C}_{2} \mathrm{H}_{5}$ & $\mathrm{H}$ & $\mathrm{H}$ \\
\hline
\end{tabular}

(1)

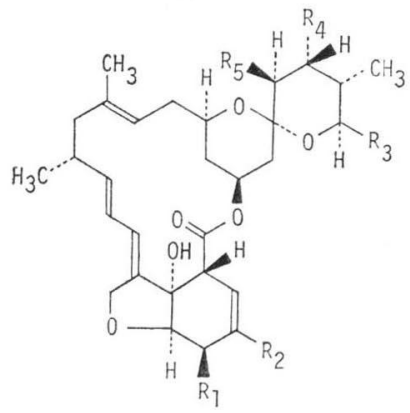

(2)

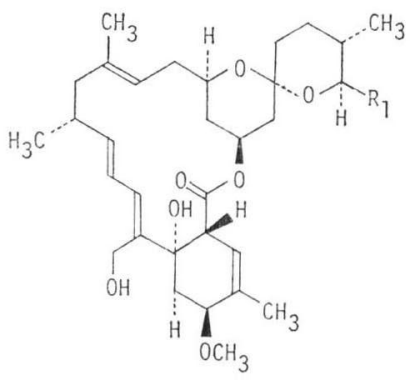

(3)<smiles>CC=CC=C(C)c1cc(O)c(C)cc1C(=O)O[C@@H]1C[C@H](CC=C(C)C[C@H](C)C=CC=C(C)CC(C)C)OC2(CCC(C)C(C)O2)C1</smiles>

in aerated and stirred 30-liter jar fermentors. Twenty liters of medium was sterilized in the fermentor by heating to $100^{\circ} \mathrm{C}$ for 30 minutes and then $120^{\circ} \mathrm{C}$ for 20 minutes. One liter of a good preculture grown in two 2-liter Erlenmeyer flasks incubated at $28^{\circ} \mathrm{C}$ for 2 days was transferred to the jar-fermentors. Growth of the microorganism was estimated by measuring the packed mycelial volume from $10 \mathrm{ml}$ of culture broth centrifuged in a $15-\mathrm{ml}$ graduated centrifuge tube at 3,000 rpm for 10 minutes. The amount of milbemycins produced in the broth was estimated by thin-layer chromatography (TLC). Reducing sugar in the broth was estimated by the Somogyi method.

Thin-layer chromatography assay

To determine the amount of milbemycins produced in the culture broth, $3 \mathrm{ml}$ of the broth was mixed with $7 \mathrm{ml}$ of acetone and shaken for about 2 minutes. The mixture was centrifuged at $3,000 \mathrm{rpm}$ for 5 minutes and $1 \mathrm{ml}$ of the supernatant solution was evaporated to dryness in vacuo. The residue was dissolved in $1 \mathrm{ml}$ of $\mathrm{MeOH}$, and $10 \mu \mathrm{l}$ of the $\mathrm{MeOH}$ solution was applied to a silica-gel $60-\mathrm{F}_{254}$ plate (E. Merck, Darmstadt, Germany). The plate was developed by the ascending technique for 4 hours at room temperature, using a solvent system composed of carbon tetrachloride and dioxane (82:18). The milbemycins on the plate were detected under short-wave UV light. For a quantitative assay, the plate 
Fig. 2. Densitometer trace of a broth extract of Streptomyces sp. B-41.

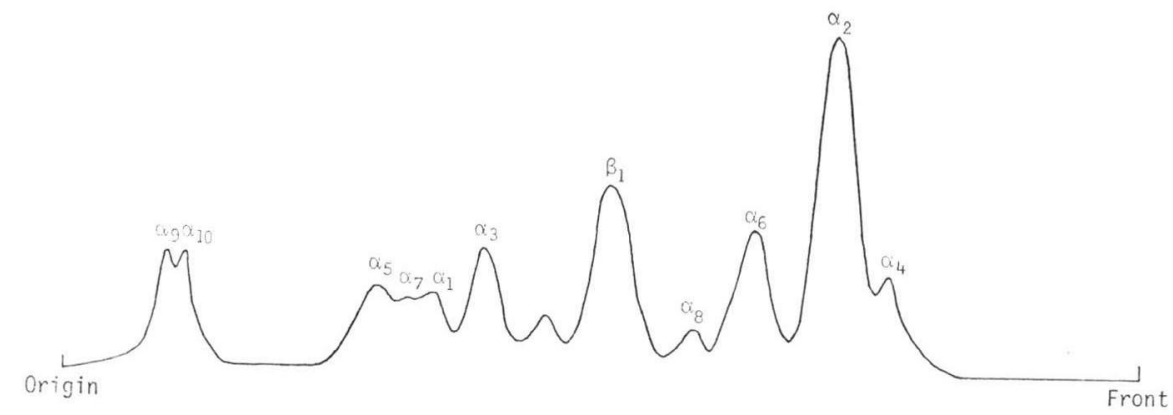

was scanned at $240 \mathrm{~nm}$ with a dual-wavelength TLC Scanner (Model CS-900, Shimazu Co., Ltd., Japan). A scan of the broth extract is shown in Fig. 2. The peak heights on the scan were compared with those of a standard extract which had been calibrated from the ultraviolet absorbance of purified milbemycin components. Of the antibiotics listed in Fig. 1, milbemycins $\alpha_{1}$ and $\alpha_{3}$ have much the greatest acaricidal and insecticidal activity. Therefore, the quantity of milbemycins was expressed as the sum of milbemycins $\alpha_{1}$ and $\alpha_{3}$, unless otherwise specified.

\section{Isolation}

Fermentation broth (120 liters) containing milbemycins was filtered with the aid of infusorial earth (Celite 545 from Johns-Manville Products Corp., Calif., U.S.A.). The cake was extracted twice with 50 liters of $\mathrm{MeOH}$; to the 100 liters of extract 50 liters of water was added. The resulting aqueous $\mathrm{MeOH}$ was extracted twice with 100 liters of $n$-hexane. The $n$-hexane was evaporated under reduced pressure and the residue was dissolved in 2 liters of $\mathrm{MeOH}$. The resulting solution was allowed to stand overnight at $-20^{\circ} \mathrm{C}$ and the precipitate was removed by filtration. The filtrate was concentrated to obtain 90 grams of a brown oily substance. This was dissolved in $150 \mathrm{ml}$ of $n$-hexane and applied to a silica gel (Wakogel C-200) column. The column was eluted with a mixture of $n$-hexane and acetone (95:5) to obtain successively, fractions I ( $800 \mathrm{ml})$, II (2 liters), III (1 liter) and IV (3 liters). Monitoring of the eluate was by thin-layer chromatography. The column was then eluted with $n$-hexane - acetone ( 90 : $10)$ and (80:20) to obtain fraction V (1 liter) and VI (1 liter), respectively.

Fraction I, containing a large quantity of $\alpha_{4}$ and a small quantity of $\alpha_{2}$, was evaporated under reduced pressure. Two grams of the crude powder thus obtained was dissolved in $5 \mathrm{ml}$ of $n$-hexane and applied to a $50-\mathrm{ml}$ silica-gel column, which was eluted with $n$-hexane - acetone (95:5) to separate milbemycins $\alpha_{4}$ from $\alpha_{2}$ and others. Appropriate fractions were pooled on the basis of TLC analysis and the solvent was removed under reduced pressure. The solid thus obtained was recrystallized from acetone - water yielding $1.2 \mathrm{~g}$ of milbemycin $\alpha_{4}$ as amorphous powder.

Fraction II, containing milbemycin $\alpha_{2}$ as a major component and $\alpha_{4}$ as a minor component, was evaporated and $15 \mathrm{~g}$ of the residue in $40 \mathrm{ml}$ of $n$-hexane was chromatographed on a $500-\mathrm{ml}$ silica gel column with $n$-hexane - acetone (95:5). The fractions containing milbemycin $\alpha_{2}$, based on TLC analysis, were pooled and evaporated under reduced pressure. The solid thus obtained was recrystallized from acetone - water to yield milbemycin $\alpha_{2}(7 \mathrm{~g})$ as colorless crystals.

Fraction III, containing milbemycins $\alpha_{8}$ and $\alpha_{8}$, was evaporated under reduced pressure and $1 \mathrm{~g}$ of the residue in $3 \mathrm{ml}$ of $n$-hexane was chromatographed on a 30 -ml silica-gel column with $n$-hexane acetone (94: 6). Fractions selected from TLC analysis to contain milbemycins $\alpha_{8}$ or $\alpha_{8}$ were pooled separately and evaporated under reduced pressure. Recrystallization from acetone - water yielded $400 \mathrm{mg}$ of $\alpha_{8}$ as colorless crystals and $200 \mathrm{mg}$ of $\alpha_{8}$ as amorphous powder.

Fraction IV, containing $\alpha_{1}, \alpha_{3}, \beta_{1}$ and $\beta_{2}$, was evaporated under reduced pressure. Five grams of the oily residue in $13 \mathrm{ml}$ of chloroform was chromatographed on a $75-\mathrm{ml}$ alumina (Wako, Co., Ltd., Osaka, Japan) column with chloroform - ethyl acetate (9:1) to separate the $\beta$ s and $\alpha$ s components. The fractions containing $\beta_{1}$ as a major component and $\beta_{2}$ as a minor component were pooled and concentrat- 
ed to dryness under reduced pressure. The yellowish syrup thus obtained in $5 \mathrm{ml}$ of $n$-hexane was chromatographed on a $50-\mathrm{ml}$ silica-gel column with $n$-hexane - acetone (94:6) to separate $\beta_{1}$ from $\beta_{2}$. Appropriate fractions, based on TLC analysis, were pooled and the solvent was removed under reduced pressure. Each yellowish syrup thus obtained was dissolved in acetone, decolorized with active carbon and the solvent was removed in vacuo. The residues thus obtained were recrystallized from acetone water to yield $1.2 \mathrm{~g}$ of $\beta_{1}$ and $300 \mathrm{mg}$ of $\beta_{2}$. Two and a half grams of the yellowish syrup obtained by partial separation of fraction IV was dissolved in $10 \mathrm{ml}$ of $n$-hexane and chromatographed on a $60-\mathrm{ml}$ silica-gel column with $n$-hexane - acetone (94:6) to separate milbemycins $\alpha_{1}$ and $\alpha_{3}$. Fractions containing $\alpha_{1}$ and $\alpha_{3}$, based on TLC analysis, were separately pooled and the solvent was removed in vacuo. The yellowish syrups thus obtained were dissolved in acetone, decolorized with active carbon and recrystallized from acetone-water to yield crystals of milbemycin $\alpha_{1}(700 \mathrm{mg})$ and $\alpha_{3}(1.1 \mathrm{~g})$.

Fraction $\mathrm{V}$, containing $\alpha_{5}, \alpha_{7}$ and $\beta_{3}$, was evaporated under reduced pressure. Two grams of the yellowish residue in $10 \mathrm{ml}$ of $\mathrm{MeOH}$ was chromatographed on silica-gel $60-\mathrm{F}_{254}$ plates $(2-\mathrm{mm}$ thickness, E. Merck, Darmstadt, Germany). The plates were developed with carbon tetrachloride - dioxane (82:18) at room temperature for 4 hours to separate $\alpha_{5}, \alpha_{7}$ and $\beta_{3}$. Zones located under short-wave UV light were scraped from the plate and eluted with $400 \mathrm{ml}$ of $\mathrm{MeOH}$. The solvent was removed under reduced pressure. Each yellowish syrup thus obtained was dissolved in $50 \mathrm{ml}$ of acetone and decolorized with $500 \mathrm{mg}$ of active carbon. Milbemycin $\alpha_{5}(850 \mathrm{mg})$ were obtained from the acetonewater solution by concentration in vacuo at $45^{\circ} \mathrm{C}$. Crystals of milbemycin $\beta_{3}(100 \mathrm{mg})$ was obtained as a minor component from the $\alpha_{5}$ fraction. Milbemycin $\alpha_{7}$ obtained by evaporation of the acetone solution was crystallized from acetone-water to yield $\alpha_{7}(150 \mathrm{mg})$ as amorphous powder.

Fraction VI, containing $\alpha_{\theta}$ and $\alpha_{10}$, was evaporated under reduced pressure. Eight hundred milligrams of yellowish syrup thus obtained, in $8 \mathrm{ml}$ of $\mathrm{MeOH}$, was applied to the origin of silica-gel $60-\mathrm{F}_{254}$ plates (2-mm thickness). The plates were developed with carbon tetrachloride - dioxane (80: 20) at room temperature for 4 hours. Milbemycin $\alpha_{9}$ and $\alpha_{10}$ zones, located under short-wave UV light, were scraped from the plate and eluted with $400 \mathrm{ml}$ of $\mathrm{MeOH}$. The solvent was removed under reduced pressure. Each yellowish substance thus obtained was dissolved in acetone and decolorized with active carbon. Milbemycins $\alpha_{9}(260 \mathrm{mg})$ and $\alpha_{10}(240 \mathrm{mg})$ were obtained as amorphous powder from the acetone-water solution.

Analytical procedures

Melting points were determined using a Büchi capillary melting point apparatus and were uncorrected. UV absorption spectra were obtained in EtOH with a Hitachi 200-20 spectrophotometer. IR spectra were obtained in potassium bromide disks using a JASCO IRA-2 spectrometer. Mass spectra were recorded on a JEOL MLS-01SG at $75 \mathrm{eV}$ using a direct inlet system.

\section{Results}

\section{Fermentation}

Numerous ingredients of the culture medium were screened for their ability to support the production of milbemycins. Using $1.0 \%$ soybean meal as a nitrogen source, carbohydrates were screened as possible carbon sources. We examined glucose, sucrose, maltose, glycerol, soluble starch, corn starch, inositol and mannitol. Of these, glucose, sucrose, soluble starch and corn starch appeared to be favorable for milbemycin production. Using $2 \%$ glucose as a carbon source, various types of nitrogen compounds were tested. We found soybean meal, cotton-seed meal, corn-steep liquor and skim milk to be suitable.

On the basis of these results numerous complex media were formulated and screened for their ability to support rapid growth and subsequent antibiotic production. The best was medium BM-1, which contained the following (in $\mathrm{g} / 1,000 \mathrm{ml}$ water): glucose 40 , corn starch 5 , soybean meal 10 , corn-steep liquor 2 and $\mathrm{NaCl} 3$. 
Fig. 3. Time course of milbemycin production on the BM-1 medium in a 30 -liter-jar fermentor.

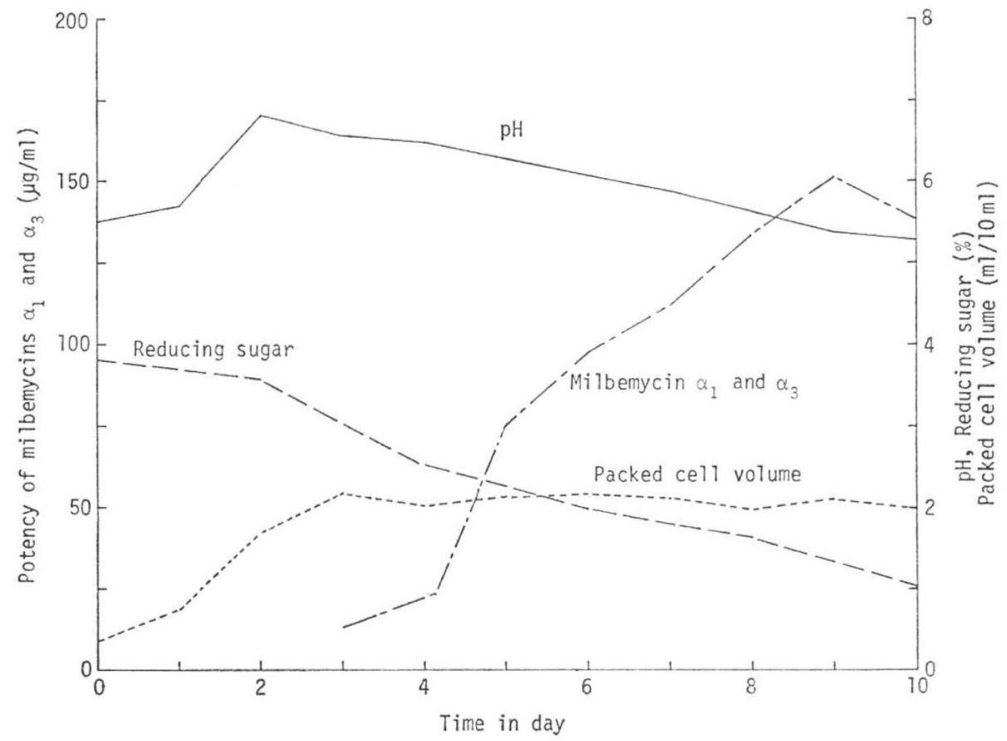

Reducing sugar and packed cell volume were determined as described in the text.

The effects of various additions to medium BM-1 on the production of milbemycins were determined by TLC. Of various vitamins tested at $10 \mu \mathrm{g} / \mathrm{ml}$, folic acid, vitamins $\mathrm{B}_{1}, \mathrm{~B}_{2}$ and $\mathrm{B}_{6}$ stimulated the production of milbemycins, especially $\alpha_{1}$ and $\alpha_{3}$. Twelve amino acids tested at 1 and $5 \mathrm{mg} / \mathrm{ml}$ were without effect. The addition of $10 \mathrm{mg}$ of $\mathrm{CaCO}_{3}$ per $\mathrm{ml}$ or $5 \mathrm{mg}$ of $\mathrm{MgSO}_{4} \cdot 7 \mathrm{H}_{2} \mathrm{O}$ per $\mathrm{ml}$ to the medium, however, stimulated the production of milbemycins $\alpha_{1}$ and $\alpha_{3}$. A mixture of trace elements also stimulated the production, although this effect was not always reproducible.

The packed cell volume in the culture broth increased in the first 3 days and remained constant thereafter (Fig. 3). The antibiotics were first detected in the broth after 3 days cultivation and increased at a linear rate for the next 6 days. The yield (milbemycins $\alpha_{1}$ and $\alpha_{3}, 150 \mu \mathrm{g} / \mathrm{ml}$ ) was a maximum at 9 days (Fig. 3).

\section{Isolation}

The milbemycins were isolated from the mycelium by extraction with $\mathrm{MeOH}$. The isolation procedures are outlined in Figs. 4 and 5.

\section{Physical and Chemical Properties}

All of the milbemycins are easily soluble in common organic solvents, $n$-hexane, benzene, acetone, EtOH, $\mathrm{MeOH}$ and chloroform. They are sparingly soluble in water.

Fig. 4. Extraction and isolation of milbemycins. Fermented broth (120 liters)

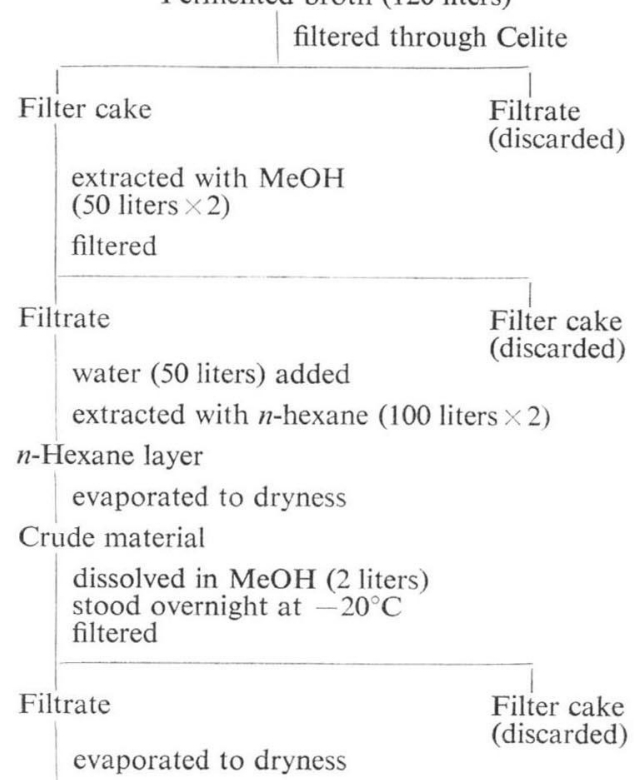

Brown oily substance ( $90 \mathrm{~g}$ ) 
Fig. 5. Separation of milbemycins.

Brown oily substance $90 \mathrm{~g}$
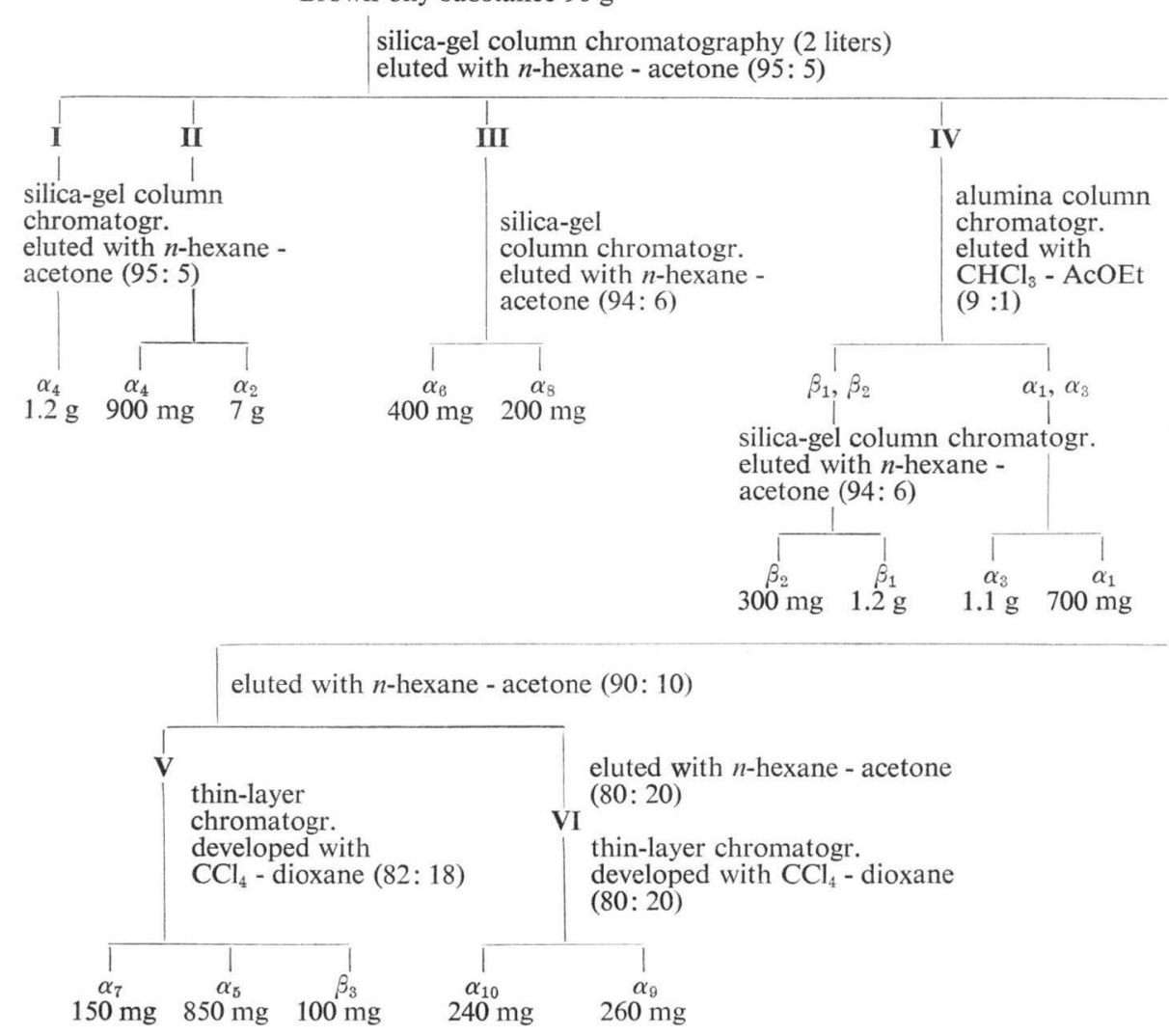

The mass spectrum of each milbemycin shows several prominent fragment-ion peaks and an intense molecular ion peak (Table 1). Molecular weights and formulae were determined by high-resolution mass spectrometry (Table 1).

UV spectra of the milbemycins $\alpha_{1 \sim 10}$ showed a maximum $(244 \sim 245 \mathrm{~nm})$ having two shoulders in the region of $238 \sim 254 \mathrm{~nm}$. The wavelengths of the maxima and their molar extinction values are shown in Table 2. UV spectra of milbemycins $\alpha_{9}$ and $\alpha_{10}$ showed a peak at $266 \mathrm{~nm}$ in addition to the peaks observed in the spectra of milbemycins $\alpha_{1 \sim 8}$. UV spectra of milbemycins $\beta_{1 \sim 3}$ showed only one peak at $245 \sim 247 \mathrm{~nm}$.

In all IR spectra of milbemycins, absorption bands due to the hydroxyl and lactone groups were observed at $3330 \sim 3600 \mathrm{~cm}^{-1}$ and at $1707 \sim 1710 \mathrm{~cm}^{-1}$, respectively (Table 2). The IR spectra of milbemycins $\alpha_{5}, \alpha_{8}, \alpha_{\tau}$ and $\alpha_{8}$ showed the absorption band due to an ester group at $1721 \sim 1722 \mathrm{~cm}^{-1}$. In addition to the absorption bands due to hydroxyl and lactone groups, absorption bands due to an aromatic ring were observed in the IR spectrum of milbemycin $\beta_{3}$ at 1670,1608 and $1582 \mathrm{~cm}^{-1}$.

The melting points and optical rotations of milbemycins are listed in Table 2 . Rf values on silicagel thin-layer plates developed with various solvent systems are shown in Table 3 .

\section{Discussion}

Of the several thousand microbial fermentation products which have been described, only a few have been reported to have insecticidal and acaricidal activity. They are aspiculamycin ${ }^{6)}$, aureothin ${ }^{7)}, \mathrm{MYC}^{2}$ 
Table 1. Fragment ion peaks $(m / e)$ in the mass spectra of milbemycins.

\begin{tabular}{|c|c|c|c|c|c|c|c|c|c|c|c|c|}
\hline Milbemycin & $\mathbf{M}^{+}$ & \multicolumn{10}{|c|}{ Fragment ions } & \multirow{2}{*}{$\begin{array}{c}\begin{array}{c}\text { Molecular } \\
\text { formula }\end{array} \\
\mathrm{C}_{31} \mathrm{H}_{44} \mathrm{O}_{7}\end{array}$} \\
\hline$\alpha_{1}\left(\mathrm{~A}_{\imath}\right)$ & 528 & & & & 400 & 356 & 250 & & 181 & 153 & 151 & \\
\hline$\alpha_{2}\left(\mathrm{~B}_{2}\right)$ & 542 & & & & 400 & 356 & 250 & & 181 & 153 & 151 & $\mathrm{C}_{32} \mathrm{H}_{46} \mathrm{O}_{7}$ \\
\hline$\alpha_{3}\left(\mathrm{~A}_{4}\right)$ & 542 & & & & 414 & 356 & 264 & & 195 & 167 & 151 & $\mathrm{C}_{32} \mathrm{H}_{46} \mathrm{O}_{7}$ \\
\hline$\alpha_{4}\left(\mathrm{~B}_{3}\right)$ & 556 & & & & 414 & 356 & 264 & & 195 & 167 & 151 & $\mathrm{C}_{33} \mathrm{H}_{48} \mathrm{O}_{7}$ \\
\hline$\alpha_{5}\left(\mathrm{~A}_{2}\right)$ & 672 & & & 444 & 414 & & 264 & & 195 & 167 & 151 & $\mathrm{C}_{38} \mathrm{H}_{56} \mathrm{O}_{10}$ \\
\hline$\alpha_{B}\left(\mathrm{~B}_{1}\right)$ & 686 & & & 458 & 414 & & 264 & & 195 & 167 & 151 & $\mathrm{C}_{39} \mathrm{H}_{58} \mathrm{O}_{10}$ \\
\hline$\alpha_{7}$ & 686 & & & 458 & 428 & & 278 & 209 & 181 & 165 & & $\mathrm{C}_{39} \mathrm{H}_{58} \mathrm{O}_{10}$ \\
\hline$\alpha_{8}$ & 700 & & & 472 & 428 & & 278 & 209 & 181 & 165 & & $\mathrm{C}_{40} \mathrm{H}_{60} \mathrm{O}_{10}$ \\
\hline$\alpha_{9}^{*}\left(\mathrm{C}_{1}\right)$ & 679 & 637 & 568 & & 400 & & 250 & & 181 & 153 & 151 & $\mathrm{C}_{36} \mathrm{H}_{47} \mathrm{O}_{9} \mathrm{~N}$ \\
\hline$\alpha_{10} *\left(\mathrm{C}_{2}\right)$ & 693 & 651 & 582 & & 414 & & 264 & & 195 & 167 & 151 & $\mathrm{C}_{37} \mathrm{H}_{48} \mathrm{O}_{9} \mathrm{~N}$ \\
\hline$\beta_{1}\left(A_{1}\right)$ & 544 & & 526 & & 402 & 387 & 294 & & 181 & 153 & & $\mathrm{C}_{32} \mathrm{H}_{48} \mathrm{O}_{7}$ \\
\hline$\beta_{2}$ & 558 & & & & 416 & & & & 195 & 167 & & $\mathrm{C}_{33} \mathrm{H}_{50} \mathrm{O}_{7}$ \\
\hline$\beta_{3}$ & 494 & & 476 & 450 & 408 & & 245 & 227 & & & & $\mathrm{C}_{31} \mathrm{H}_{42} \mathrm{O}_{5}$ \\
\hline
\end{tabular}

* monoacetate

Table 2. Physico-chemical properties of milbemycins.

\begin{tabular}{|c|c|c|c|c|}
\hline $\begin{array}{l}\text { Milbemycin } \\
\quad(\mathrm{B}-41)\end{array}$ & $\underset{\left({ }^{\circ} \mathrm{C}\right)}{\text { Melting point }}$ & {$[\alpha]_{\mathrm{D}}^{20 * *}$} & $\lambda_{\max }^{\mathrm{EtOH}} \mathrm{nm}(\varepsilon)$ & $\nu_{\max }\left(\mathrm{cm}^{-1}\right)$ \\
\hline$\alpha_{1}\left(\mathbf{A}_{3}\right)$ & $212 \sim 215$ & +106 & $238(27800), 244(30500), 253(\mathrm{sh})$. & $3600,3480,1708$ \\
\hline$\alpha_{2}\left(B_{2}\right)$ & $139 \sim 142$ & +131 & $238(\mathrm{sh}), 244(26500)$ & 3600,1708 \\
\hline$\alpha_{3}\left(\mathbf{A}_{4}\right)$ & $212 \sim 215$ & +106 & $238(27800), 244(30500), 253(\mathrm{sh})$. & 3480,1707 \\
\hline$\alpha_{4}\left(\mathbf{B}_{3}\right)$ & $*$ & +126 & 238 (sh.), $241(26500), 253$ (sh.) & 3480,1707 \\
\hline$\alpha_{5}\left(\mathrm{~A}_{2}\right)$ & $*$ & +54 & $238(27800), 245(30500), 253(\mathrm{sh})$. & $3580,1722,1707$ \\
\hline$\alpha_{6}\left(\mathbf{B}_{1}\right)$ & $176 \sim 178$ & +75 & $238(27800), 245(30500), 253(\mathrm{sh})$. & $3450,1721,1707$ \\
\hline$\alpha_{7}$ & $*$ & - & $238(27800), 245(30500), 253$ (sh.) & $3580,1722,1707$ \\
\hline$\alpha_{8}$ & $*$ & - & $238(27800), 245(30500), 253(\mathrm{sh})$. & $3450,1721,1707$ \\
\hline$\alpha_{9}\left(\mathrm{C}_{1}\right)$ & * & +57 & $\begin{array}{l}238(31300), 245(35200) \\
254(31000), 266(\mathrm{sh} .)\end{array}$ & 3330,1710 \\
\hline$\alpha_{10}\left(\mathrm{C}_{2}\right)$ & $*$ & +54 & $\begin{array}{l}238(31300), 245(35200) \\
254(31000), 266(\text { sh. })\end{array}$ & 3330,1710 \\
\hline$\beta_{1}\left(\mathbf{A}_{1}\right)$ & * & +160 & $245(26500)$ & 3450,1707 \\
\hline$\beta_{2}$ & $*$ & - & $245(26500)$ & 3450,1707 \\
\hline$\beta_{3}$ & $185 \sim 187$ & - & $247(29200)$ & $\begin{array}{l}3450,1707,1670, \\
1608,1582\end{array}$ \\
\hline
\end{tabular}

* amorphous, ** $c=0.25$, acetone

-; not measured, sh; shoulder

$8005^{8)}$, orthosomycins ${ }^{9)}$, tetranactin ${ }^{10)}$ and avermectins ${ }^{11)}$. From the results described above, as well as from the structures and characteristic biological activities, one can conclude that the milbemycins are a new family of macrolide antibiotics. The insecticidal and acaricidal activities will be reported elsewhere. 
Table 3. Rf values from thin-layer chromatography of milbemycins.

\begin{tabular}{|c|c|c|c|c|c|c|c|}
\hline \multirow{2}{*}{$\begin{array}{l}\text { Milbemycin } \\
\text { (B-41) }\end{array}$} & \multicolumn{3}{|c|}{ Solvent systems } & \multirow{2}{*}{$\begin{array}{l}\text { Milbemycin } \\
\quad(B-41)\end{array}$} & \multicolumn{3}{|c|}{ Solvent systems } \\
\hline & I & II & III & & I & II & III \\
\hline$\alpha_{1}\left(\mathbf{A}_{3}\right)$ & 0.35 & 0.42 & 0.39 & $\alpha_{7}$ & 0.32 & 0.35 & 0.37 \\
\hline$\alpha_{2}\left(\mathrm{~B}_{2}\right)$ & 0.76 & 0.61 & 0.79 & $\alpha_{8}$ & 0.69 & 0.51 & 0.77 \\
\hline$\alpha_{3}\left(\mathbf{A}_{4}\right)$ & 0.40 & 0.44 & 0.41 & $\alpha_{9} \quad\left(\mathrm{C}_{1}\right)$ & 0.10 & 0.22 & 0.12 \\
\hline$\alpha_{4}\left(\mathbf{B}_{3}\right)$ & 0.81 & 0.63 & 0.81 & $\alpha_{10}\left(\mathrm{C}_{2}\right)$ & 0.13 & 0.24 & 0.13 \\
\hline$\alpha_{5}\left(\mathbf{A}_{2}\right)$ & 0.28 & 0.32 & 0.35 & $\beta_{1} \quad\left(A_{1}\right)$ & 0.53 & 0.47 & 0.27 \\
\hline$\alpha_{6}\left(\mathrm{~B}_{1}\right)$ & 0.67 & 0.47 & 0.75 & & & & \\
\hline
\end{tabular}

Solvent system I ; Dioxane- $\mathrm{CCl}_{4}(15: 85)$

Solvent system II ; Acetone- $n$-hexane (30:70)

Solvent system III; Ethyl acetate $-\mathrm{CHCl}_{3}(25: 75)$

Pre-coated silica-gel 60 F-254 plates (Merck) were used.

\section{References}

1) Japan Patent application No. 48-60127, 1973

2) Mishima, H.; M. Kurabayashi, C. Tamura, S. Sato, H. Kuwano, A. Saitoh \& A. Aoki: Structures of milbemycins $\alpha_{1}, \alpha_{2}, \alpha_{3}, \alpha_{4}, \alpha_{5}, \alpha_{6}, \alpha_{7}, \alpha_{8}, \alpha_{9}, \alpha_{10}$, and $\beta_{1}$. Abstract Papers (309 316) 18th Symp. Chem. Natural Products, Kyoto, Oct. 17 19, 1974

3) Mishima, H.; M. Kurabayashi, C. Tamura, S. Sato, H. Kuwano \& A. Aoki: Structures of milbemycins $\beta_{1}, \beta_{2}$, and $\beta_{3}$. Tetrahed. Lett. 1975: 711 714, 1975

4) Japan Patent Kokai No. 54-89041, 1979

5) Egerton, J. R.; D. A. Ostlind, L. S. Blair, C. H. Eary, D. Suhayda, S. Cifelli, R. F. Riek, \& W. C. CAMPBell: Avermectins, new family of potent anthelminic agents: efficacy of the $\mathrm{B}_{1 \mathrm{a}}$ component. Antimicr. Agents \& Chemoth. 15: 372 378, 1979

6) Haneishi, T.; M. Arai, N. Kitano \& S. Yamamoto: Aspiculamycin, a new cytosine nucleoside antibiotic. III. Biological activities in vitro and in vivo. J. Antibiotics 27: 339 342, 1974

7) Oishi, H.; T. Hosokawa, T. OKutomi, K. Suzuki \& K. Ando: Pesticidal activity of aureothin. Agr. Biol. Chem. 33: 1790 1791, 1969

8) Meltzer, J.: MYC 8005, An antibiotic against spider mites. II. Growth inhibition and pseudo-sterilization in insects and mites. Neth. J. Plant Pathol. 78: 77 88, 1972

9) Wright, D. E.: The orthosomycins, a new family of antibiotics. Tetrahedron 35: 1207 1237, 1979

10) Ando, K.; H. Oishi, S. Hirano, T. Okutomi, K. Suzuki, H. Okazaki, M. Sawada \& T. Sagawa: Tetranactin, a new miticidal antibiotic. I. Isolation, characterization and properties of tetranactin. J. Antibiotics 24: 347 352, 1971

11) Ostlind, D. A.; S. Cifelli \& R. LANG: Insecticidal activity of the anti-parasitic avermectins. Veterinary Record 105: 168, 1979 